BMJ Open

Sport \&

Exercise

Medicine

\section{Criterion validity of two physical activity and one sedentary time questionnaire against accelerometry in a large cohort of adults and older adults}

To cite: Sagelv EH,

Hopstock LA, Johansson J, et al. Criterion validity of two physical activity and one sedentary time questionnaire against accelerometry in a large cohort of adults and older adults. BMJ Open Sport \& Exercise Medicine 2020;6:e000661. doi:10.1136/ bmjsem-2019-000661

- Additional material is published online only. To view please visit the journal online (http://dx.doi.org/10.1136/ bmjsem-2019-000661).

Accepted 6 February 2020

\section{Check for updates}

\section{(C) Author(s) (or their} employer(s)) 2020. Re-use permitted under CC BY-NC. No commercial re-use. See rights and permissions. Published by BMJ.

For numbered affiliations see end of article.

\section{Correspondence to}

Edvard H Sagelv;

edvard.h.sagelv@uit.no

\section{ABSTRACT}

Objectives We compared the ability of physical activity and sitting time questionnaires (PAQ) for ranking individuals versus continuous volume calculations (physical activity level (PAL), metabolic equivalents of task (MET), sitting hours) against accelerometry measured physical activity as our criterion.

Methods Participants in a cohort from the Troms $\emptyset$ Study completed three questionnaires; (1) The Saltin-Grimby Physical Activity Level Scale (SGPALS) $(n=4040)$; (2) The Physical Activity Frequency, Intensity and Duration (PAFID) questionnaire $(\mathrm{n}=5902))$ calculated as MET-hours week $^{-1}$ and (3) The International Physical Activity questionnaire (IPAQ) short-form sitting question $(n=4896)$. We validated the questionnaires against the following accelerometry (Actigraph wGT3X-BT) estimates: vector magnitude counts per minute, steps $\cdot$ day $^{-1}$, time (minutes.day ${ }^{-1}$ ) in sedentary behaviour, light physical activity, moderate and vigorous physical activity (MVPA) non-bouted and $\geq 10$ min bouted MVPA.

Results Ranking of physical activity according to the SGPALS and quartiles (Q) of MET-hours. week $^{-1}$ from the PAFID were both positively associated with accelerometry estimates of physical activity $(p<0.001)$ but correlations with accelerometry estimates were weak (SGPALS (PAL): $r=0.11$ to $0.26, p<0.001$ ) and weak-to-moderate (PAFID: $r=0.39$ to $0.44, p<0.01$ ). There was 1 hour of accelerometry measured sedentary time from $Q 1$ to $Q 4$ in the IPAQ sitting question $(p<0.001)$ and also weak correlations $(r=0.22, p<0.01)$.

Conclusion Ranking of physical activity levels measured with PAQs appears to have higher validity than energy expenditure calculations. Self-reported sedentary time poorly reflects accelerometry measured sedentary time. These two PAQs can be used for ranking individuals into different physical activity categories supporting previous studies using these instruments when assessing associations with health outcomes.

\section{INTRODUCTION}

Physical activity surveillance at population level may support public health initiatives and allow researchers to track physical activity levels and patterns over time. ${ }^{1}$ Physical activity

\section{Summary box}

What are the new findings

- Ranking of the two included physical activity questionnaires reduces information content but may be the optimal way of processing self-reported physical activity.

- Volume calculations (physical activity level, metabolic equivalents of task hours) allow the biasses associated with self-reported physical activity to be more pronounced.

- Self-reported sitting time shows low validity and does not reflect accelerometry measured sedentary time.

is traditionally measured using self-reported methods such as questionnaires. ${ }^{2}$ However, the validity of physical activity questionnaires (PAQ) is threatened by recall and social desirability bias, resulting in imprecise assessments. ${ }^{3-6}$ Nevertheless, PAQs have over the years led to valuable knowledge on the effect of physical activity on health outcomes and mortality. ${ }^{7-14}$

Validation of PAQs is crucial to guide researchers when interpreting associations between self-reported physical activity and health outcomes. Moreover, PAQs may inherit different measurement properties. For example, one of the first developed PAQs, by Saltin and Grimby $^{15}$ named 'Saltin-Grimby Physical Activity Level Scale' (SGPALS), ${ }^{16}{ }^{17}$ ranks individuals by physical activity levels. A more recent PAQ, the Physical Activity Frequency, Intensity and Duration (PAFID) questionnaire, ${ }^{18}$ allows the answers to be summed up as total physical activity volume (ie, energy expenditure, metabolic equivalents of task (MET)-hours per week). Finally, sedentary behaviour has been suggested as a risk factor for disease and mortality, which is also commonly assessed by PAQs,${ }^{190}$ such as the International Physical 
Activity Questionnaire (IPAQ) short-form sitting question. ${ }^{21}$ Both PAQs (SGPALS, ${ }^{16}{ }^{22-26}$ PAFID $^{18}{ }^{27}$ ) and the IPAQ short-form sitting question ${ }^{21}$ have previously been validated, however, the studies that compare these questionnaires against accelerometry are characterised by small sample sizes. ${ }^{182123}$ As population samples are heterogeneous and consequently result in heterogeneous findings, validation studies based on small samples may have limited representability. Furthermore, considering that already established longitudinal population cohorts have implemented PAQs from inception allowing for long follow-up time (SGPALS: $>45$ years, ${ }^{28-30}$ PAFID: $>35$ years ${ }^{31}$ ), validation of PAQs and sitting questionnaires against accelerometry measured physical activity and sitting time from large heterogeneous samples will allow researchers to more accurately interpret results from longitudinal cohort studies where only questionnaires are the physical activity and sedentary time measure.

Moreover, although PAQs can inherit different measurement properties, the methods for processing the PAQs can result in similar expressions (eg, ranking of the SGPALS can be summarised as volume, ${ }^{25}$ volume calculations can be grouped as quartiles), and thus the processing of questionnaires may also influence the validity differently.

We aimed to assess the validity of two PAQs inheriting different measurement properties; ranking of physical activity levels (SGPALS), volume calculations (PAFID) and one sedentary time questionnaire (IPAQ sitting short-form), by using accelerometry as our criterion, in a large heterogeneous sample of adults and older adults. Additionally, we aimed to assess how ranking and volume calculations of the PAQs reflects accelerometry measured physical activity and sedentary time.

\section{METHODS \\ Design}

We used participants from the seventh wave of the population-based cohort study named The Tromsø Study, which is conducted in Troms $\varnothing$, Northern Norway. The study includes seven waves of data collection (Tromsø 1: 1974, Tromsø 2: 1979 to 1980 , Tromsø 3: 1986 to 1987 , Tromsø 4: 1994 to 1995, Tromsø 5: 2001, Tromsø 6: 2007 to 2008, Tromsø 7: 2015 to 2016) (details described elsewhere ${ }^{32}$ ).

\section{Participants}

All inhabitants in Tromsø municipality aged 40 years and older were invited to Tromsø 7. A total of $21083(65 \%$ of 32591 invited participants) participants attended a first visit including questionnaires, biological sampling and clinical examinations. A random selection of 8346 participants attended a second visit at a later time point ( $>7$ days), where 6778 participants were invited to wear an accelerometer, of which 6332 (93\%) participants accepted. Of those who provided valid accelerometry data, 4040 participants completed both the leisure time and occupational time SGPALS; 5902 participants completed the PAFID questionnaire, and 5186 and 5088 participants completed the sitting question from the IPAQ short-form for week and weekend, respectively, where 4896 completed both.

All participants gave written informed consent.

\section{Patient and public involvement}

The Troms $\varnothing$ study advisory board includes patient (University hospital of Northern Norway) and public (eg, Norwegian Health Association, Tromsø municipality) representatives. Some participants are invited as ambassadors when data collection is ongoing, where they actively contribute to recruitment of participants. We have together with the Norwegian Health Association provided individual feedback on levels of physical activity to participants in Tromsø 7. There was no public involvement when designing this study.

\section{Data collection}

Height and weight were measured in light clothing without shoes. Body mass index (BMI) was calculated $\left(\mathrm{kg} / \mathrm{m}^{2}\right)$ and defined as normal and underweight $\left(<25 \mathrm{~kg} / \mathrm{m}^{2}\right)$, overweight (25 to $\left.29.9 \mathrm{~kg} / \mathrm{m}^{2}\right)$ and obese $\left(\geq 30 \mathrm{~kg} / \mathrm{m}^{2}\right)$. Educational level was collected from questionnaires and categorised in; (1) primary school, (2) high school diploma, (3) university education $<4$ years and (4) university education $\geq 4$ years.

\section{The physical activity and sitting questionnaires}

The Saltin-Grimby physical activity level scale

The SGPALS asks participants to rank their leisure time and occupational time physical activity level separately, choosing one of four options. Based on the idea of the original questionnaire by Saltin and Grimby ${ }^{15}$, the SGPALS used in Troms $\varnothing 7$ is a slight modification of Saltin and Grimby ${ }^{15}$ according to Rödjer et al. ${ }^{17}$ The SGPALS is presented in online supplementary table 1 .

We computed the SGPALS as combined leisure time and occupational time where individuals were categorised as (1) inactive, (2) moderately inactive, (3) moderately active and (4) active according to Wareham $e t a l^{33}$ with some modifications. In order to calculate physical activity volume, we assigned a physical activity level (PAL) value from the combined leisure time and occupational time SGPALS, which we derived from a previous validation study that calculated PAL as energy expenditure obtained from doubly labelled water divided by the estimated basal metabolic rate. ${ }^{25}$ The classifications and the assigned PAL value are presented in table 1 .

\section{The physical activity frequency, intensity and duration questionnaire}

The PAFID questionnaire (table 2) includes three questions referring to frequency, intensity and duration of physical activity. We generated an index to reflect METs by multiplying intensity (METs) by duration (minutes) by frequency (times per week), and the outcome was expressed as MET-hours per week. ${ }^{34}{ }^{35}$ We also grouped 
Table 1 Physical activity classification by the combined leisure time and occupational time SGPALS $(n=4040)$

\begin{tabular}{|c|c|c|c|c|}
\hline & $\begin{array}{l}\text { Light LPA } \\
(n=532)\end{array}$ & $\begin{array}{l}\text { Moderate LPA } \\
(\mathrm{n}=\mathbf{2 4 2 9})\end{array}$ & $\begin{array}{l}\text { Hard LPA } \\
(n=969)\end{array}$ & $\begin{array}{l}\text { Very } \\
\text { hard LPA } \\
(n=109)\end{array}$ \\
\hline $\begin{array}{l}\text { Light OPA } \\
(n=2263)\end{array}$ & $\begin{array}{l}\text { Inactive } \\
(n=349, \\
8.6 \%) \\
\text { PAL: } 1.4\end{array}$ & $\begin{array}{l}\text { Moderately } \\
\text { inactive } \\
(n=1346, \\
33.3 \%) \\
\text { PAL: } 1.5\end{array}$ & $\begin{array}{l}\text { Active } \\
(n=507, \\
12.6 \%) \\
\text { PAL: } 1.7\end{array}$ & $\begin{array}{l}\text { Active } \\
(\mathrm{n}=61, \\
1.5 \%) \\
\text { PAL: } 1.9\end{array}$ \\
\hline $\begin{array}{l}\text { Moderate } \\
\text { OPA } \\
(n=1018)\end{array}$ & $\begin{array}{l}\text { Moderately } \\
\text { inactive } \\
(n=105, \\
2.6 \%) \\
\text { PAL: } 1.5\end{array}$ & $\begin{array}{l}\text { Moderately } \\
\text { active } \\
(\mathrm{n}=648, \\
16.0 \%) \\
\text { PAL: } 1.6\end{array}$ & $\begin{array}{l}\text { Active } \\
(\mathrm{n}=234, \\
5.8 \%) \\
\text { PAL: } 1.8\end{array}$ & $\begin{array}{l}\text { Active } \\
(n=31, \\
0.8 \%) \\
\text { PAL: } 2.0\end{array}$ \\
\hline $\begin{array}{l}\text { Heavy OPA } \\
(n=651)\end{array}$ & $\begin{array}{l}\text { Moderately } \\
\text { active } \\
(\mathrm{n}=61,1.5 \%) \\
\text { PAL: } 1.6\end{array}$ & $\begin{array}{l}\begin{array}{l}\text { Active } \\
(n=386,\end{array} \\
9.6 \%) \\
\text { PAL: } 1.7\end{array}$ & $\begin{array}{l}\text { Active } \\
(n=190, \\
4.7 \%) \\
\text { PAL: } 1.9\end{array}$ & $\begin{array}{l}\begin{array}{l}\text { Active } \\
(n=14,\end{array} \\
0.3 \%) \\
\text { PAL: } 2.2\end{array}$ \\
\hline $\begin{array}{l}\text { Very Heavy } \\
\text { OPA } \\
(n=108)\end{array}$ & $\begin{array}{l}\text { Active } \\
(\mathrm{n}=17,0.4 \%) \\
\text { PAL: } 1.7\end{array}$ & $\begin{array}{l}\text { Active } \\
(n=50,1.2 \%) \\
\text { PAL: } 1.8\end{array}$ & $\begin{array}{l}\text { Active } \\
(\mathrm{n}=38, \\
0.9 \%) \\
\text { PAL: } 2.1\end{array}$ & $\begin{array}{l}\text { Active } \\
(n=3, \\
0.1 \%) \\
\text { PAL: } 2.3\end{array}$ \\
\hline
\end{tabular}

Data are shown as $\mathrm{n}$ and \%. The number of participants and percentage distribution derives from our study sample. The assigned PAL value derives from Johansson and Westerterp, ${ }^{25}$ who divided energy expenditure obtained from doubly labelled water by the estimated basal metabolic rate of their participants. LPA, leisure time physical activity; OPA, occupational time physical activity; PAL, physical activity level; SGPALS, SaltinGrimby Physical Activity Level Scale.

MET-hours per week in quartiles in order to assess the validity of ranking physical activity in this PAQ.

The International physical activity questionnaire, sitting question In this study, the IPAQ short-form sitting question ${ }^{21}$ was employed, asking participants to estimate their average amount of sitting hours on a typical week and weekend day during the last week. In addition to the reported volume, we also grouped sitting hours in quartiles to assess the validity of ranking sitting hours.

\section{Accelerometry data processing}

Accelerometry measured physical activity was measured with the triaxial (three planes; axial, coronal and sagittal) ActiGraph wGT3X-BT accelerometer (ActiGraph, LLC, Pensacola, USA), firmware 1.2.0 to 1.8.0. Trained technicians attached the accelerometer to the participants' right hip and instructed them to wear the accelerometer for 24 hours a day on eight consecutive days (the rest of the day following the visit in the clinic and seven more days) and only to remove the accelerometer during water-based activities (eg, showering or swimming) and contact sports. The accelerometer was returned by mail in a prepaid envelope. The ActiLife software (ActiGraph, LLC, Pensacola, USA) was used for initialisation and downloading the data. The accelerometer was initialised for raw data mode with a sampling frequency of 100 Hertz and recordings started at 00:00 the day following the visit in the clinic.

The raw acceleration files were filtered to $10 \mathrm{~s}$ epochs using the normal (default) proprietary filter in the ActiLife software. The acceleration units are expressed in triaxial vector magnitude (VM) (the square root of the sum of squared activity counts) counts per minute (CPM). We also extracted the number of steps in the accelerometer, which derives from the axial plane in a proprietary algorithm by the manufacturer. The agdfiles (epoch files) were further converted to .csv-files and further analysed in the Quality Control \& Analysis Tool software (a custom-made software developed in Matlab: The MathWorks, Inc, Natick, Massachusetts, USA).

The $10 \mathrm{~s}$ epochs were further aggregated to $60 \mathrm{~s}$ and an epoch was classified as wear time if two of the following three criteria were fulfilled: (1) an epoch $>5 \mathrm{VM}$ CPM, (2) if at least two epochs $>5 \mathrm{VM}$ CPM in the proceeding 20 min or (3) at least two epochs $>5 \mathrm{VM}$ CPM in the following $20 \mathrm{~min}$. Otherwise the acceleration was considered to be noise and classified as non-wear time. ${ }^{36}$

The triaxial VM CPM cut-points for different intensities are $<150$ VM CPM for sedentary behaviour ${ }^{37}$ and $\geq 2690$ VM CPM for moderate and vigorous physical activity

Table 2 Physical activity frequency, intensity and duration (PAFID) questionnaire. Number, MET-values and minutes in parentheses in answering alternatives represents the values for the calculation of MET-hours per week

\begin{tabular}{|c|c|c|}
\hline Frequency (days) & Intensity (METs) & Duration (minutes) \\
\hline $\begin{array}{l}\text { How frequently do you exercise? With exercise, } \\
\text { we mean walking, cross-country skiing, } \\
\text { swimming or other exercise/sports. }\end{array}$ & On average, how hard is the exercise? & $\begin{array}{l}\text { On average, how long do you } \\
\text { exercise? }\end{array}$ \\
\hline Never (0) & $\begin{array}{l}\text { I take it easy without breaking into a sweat } \\
\text { or losing my breath ( } 3 \text { METs) }\end{array}$ & $<15 \min (10 \mathrm{~min})$ \\
\hline Less than once a week $(0.5)$ & $\begin{array}{l}\text { I push myself so hard that I break into a } \\
\text { sweat and lose my breath ( } 6 \text { METs) }\end{array}$ & $15-29 \min (22.5 \mathrm{~min})$ \\
\hline Once a week (1) & I push myself to near-exhaustion (9 METs) & $30-60 \min (45 \min )$ \\
\hline Two to three times per week (2.5) & N/A & $>60 \min (60 \mathrm{~min})$ \\
\hline Almost every day (5) & $\mathrm{N} / \mathrm{A}$ & $\mathrm{N} / \mathrm{A}$ \\
\hline
\end{tabular}

METs, metabolic equivalents of tasks. 
(MVPA) ${ }^{38}$ where light physical activity is between 150 to 2689 VM CPM.

Extracted accelerometry measures were volume measures (steps per day and mean VM CPM per day) in addition to intensity measures (minutes per day in sedentary behaviour, light physical activity, MVPA and $\geq 10 \mathrm{~min}$ bouted MVPA).

\section{Statistical analyses}

We calculated Pearson correlation coefficients to assess the correlation between the PAQs volume outcomes (SGPALS: PAL score, PAFID: MET-hours'week ${ }^{-1}$, IPAQ sitting: hours spent sitting) and accelerometry outcomes (VM CPM, steps per day, minutes in sedentary behaviour, light physical activity, non-bouted and bouted MVPA) where a coefficient of 0.00 to $0.10,0.10$ to $0.39,0.40$ to 0.69 and $\geq 0.70$ was considered a negligible, weak, moderate and strong correlation, respectively. ${ }^{39}$ Univariate analyses of variance (ANOVA) were performed to assess associations of accelerometry measures (VM CPM, steps, minutes in sedentary behaviour, light physical activity, non-bouted and bouted MVPA) with the SGPALS physical activity ranking, quartiles of MET-hours per week from the PAFID questionnaire and quartiles of reported sitting from the IPAQ. For the IPAQ sitting question, a Bland-Altman plot was created (online supplementary figure 1). The Alpha level was set to 0.05 and data are presented as mean \pm SEM unless otherwise is stated. All data were confirmed to follow normal distribution by visual inspection of residuals when performing the abovementioned analyses. The analyses were performed overall and in strata of sex, age (10year groups), BMI $(<25,25$ to $29, \geq 30 \mathrm{~kg} \cdot \mathrm{m}^{-2}$ ) and education (primary, high school, $<4$ years university, $\geq 4$ years university). The Statistical Package for Social Sciences (V.25, International Business Machines Corporation, Armonk, New York, USA) was used to perform all statistical analyses.

\section{Patient and public involvement}

Patients and/or the public were involved in the design, or conduct, or reporting or dissemination plans of this research. Refer to the Methods section for further details.

\section{RESULTS}

The descriptive characteristics of the participants wearing the accelerometers and completing the PAQs are presented in table 3 .

PAL scores calculated from the SGPALS correlated weakly with VM CPM $(r=0.32)$, steps per day $(r=0.27)$, sedentary behaviour $(\mathrm{r}=-0.20)$, light physical activity $(\mathrm{r}=0.22)$, non-bouted MVPA $(\mathrm{r}=0.25)$ and bouted MVPA $(\mathrm{r}=0.16) \quad($ all $\mathrm{p}<0.05)$, which was consistent across sex, age, BMI and educational level (all $\mathrm{p}<0.05$ ) (online supplementary table 2). All accelerometry measures increased by increasing rank of self-reported physical activity $\left(\mathrm{P}_{\text {trend }}<0.001\right)$ (table 4$)$.

Calculated MET-hours per week from the PAFID questionnaire showed negligible correlation with
Table 3 Participant characteristics

\begin{tabular}{|c|c|c|c|}
\hline SGPALS & $\begin{array}{l}\text { Women } \\
(n=1983)\end{array}$ & $\begin{array}{l}\text { Men } \\
(n=2057)\end{array}$ & $\begin{array}{l}\text { Total } \\
(n=4040)\end{array}$ \\
\hline Age (yrs) & $58.9 \pm 9.5$ & $61.0 \pm 9.9$ & $60.0 \pm 9.7$ \\
\hline Height (cm) & $164.5 \pm 6.3$ & $177.4 \pm 6.7$ & $171.1 \pm 9.2$ \\
\hline Weight (kg) & $71.9 \pm 12.8$ & $87.8 \pm 13.8$ & $80.0 \pm 15.5$ \\
\hline $\mathrm{BMI}\left(\mathrm{kg} / \mathrm{m}^{2}\right)$ & $26.6 \pm 4.7$ & $27.9 \pm 4.0$ & $27.2 \pm 4.4$ \\
\hline PAFID & $\begin{array}{l}\text { Women } \\
(n=3174)\end{array}$ & Men $(n=2728)$ & $\begin{array}{l}\text { Total } \\
(n=5902)\end{array}$ \\
\hline Age (yrs) & $63.3 \pm 10.3$ & $63.7 \pm 10.2$ & $63.5 \pm 10.2$ \\
\hline Height (cm) & $163.6 \pm 6.3$ & $176.9 \pm 6.7$ & $169.8 \pm 9.3$ \\
\hline Weight (kg) & $71.7 \pm 12.8$ & $87.0 \pm 13.8$ & $78.8 \pm 15.3$ \\
\hline BMI $\left(\mathrm{kg} / \mathrm{m}^{2}\right)$ & $26.8 \pm 4.7$ & $27.8 \pm 3.9$ & $27.3 \pm 4.4$ \\
\hline $\begin{array}{l}\text { IPAQ } \\
\text { combined }\end{array}$ & $\begin{array}{l}\text { Women } \\
(n=2495)\end{array}$ & Men (n=2401) & $\begin{array}{l}\text { Total } \\
(n=4896)\end{array}$ \\
\hline Age (yrs) & $61.4 \pm 10.1$ & $62.6 \pm 10.0$ & $62.0 \pm 10.1$ \\
\hline Height (cm) & $164.2 \pm 6.2$ & $177.2 \pm 6.6$ & $170.6 \pm 9.2$ \\
\hline Weight (kg) & $71.5 \pm 12.8$ & $87.1 \pm 13.7$ & $79.1 \pm 15.4$ \\
\hline $\mathrm{BMI}\left(\mathrm{kg} / \mathrm{m}^{2}\right)$ & $26.5 \pm 4.7$ & $27.7 \pm 3.9$ & $27.1 \pm 4.3$ \\
\hline
\end{tabular}

Data are shown as mean \pm SD

BMI, body mass index; IPAQ combined, International Physical Activity Questionnaire combined: mean of week and weekend; PAFID, Physical Activity Frequency, Intensity and Duration; SGPALS, Saltin-Grimby Physical Activity Level Scale.

accelerometry measured light physical activity $(\mathrm{r}=0.06)$, weak correlation with VM CPM $(\mathrm{r}=0.34)$, moderate correlation with steps per day $(\mathrm{r}=0.43)$ and weak and moderate correlation with non-bouted MVPA $(\mathrm{r}=0.39)$ and bouted MVPA $(\mathrm{r}=0.44)$, respectively $(\mathrm{p}<0.001)$. This was consistent across sex, age, BMI and educational level $(\mathrm{p}<0.05)$ except for light physical activity, which did not correlate with MET-hours per week in some age groups ( 40 to 49 years; $p=0.19,50$ to 59 years; $p=0.13,60$ to 69 years; $\mathrm{p}=0.79)$, BMI classifications $\left(<25 \mathrm{~kg} / \mathrm{m}^{2} ; \mathrm{p}=0.54\right.$ and 25 to $29 \mathrm{~kg} / \mathrm{m}^{2} ; \mathrm{p}=0.31$ ) and educational levels (high school; $\mathrm{p}=0.07$ and university $\geq 4$ years; $\mathrm{p}=0.051$ ) (online supplementary table 3 ).

Quartiles of MET-hours per week from the PAFID questionnaire showed positive association with all accelerometry measures $\left(\mathrm{P}_{\text {trend }}<0.001\right)$ (table 5).

Accelerometry measured sedentary hours per day correlated weakly with reported sitting hours from the IPAQ sitting question (week day; $r=0.22$, weekend day; $\mathrm{r}=0.15$ ), combined (mean of week and weekend; $r=0.22$, all $\mathrm{p}<0.01$ ), which was consistent across sex, age, BMI and educational level $(p<0.01)$ (online supplementary table $4)$. There was a positive association between quartiles of reported sitting in the IPAQ and accelerometry measured sedentary time $\left(\mathrm{P}_{\text {trend }}<0.001\right)$ (table 6$)$.

\section{DISCUSSION}

We assessed the criterion validity of two PAQs inheriting different physical activity measurement properties (physical activity ranking, volume calculation) and one sedentary 
Table 4 The combined leisure time and occupational time SGPALS, and the associations with the accelerometry estimates

\begin{tabular}{|c|c|c|c|c|}
\hline$n=4040$ & Inactive $(n=349)$ & $\begin{array}{l}\text { Moderately inactive } \\
(n=1451)\end{array}$ & $\begin{array}{l}\text { Moderately active } \\
(\mathrm{n}=709)\end{array}$ & $\begin{array}{l}\text { Active } \\
(n=1531)\end{array}$ \\
\hline $\mathrm{VM} \mathrm{CPM}^{*} \dagger$ & $410.2 \pm 7.8$ & $527.9 \pm 4.1$ & $571.3 \pm 6.2$ & $618.4 \pm 4.6$ \\
\hline Steps per day ${ }^{\star} \dagger$ & $4900.5 \pm 107.8$ & $7177.0 \pm 71.1$ & $7487.2 \pm 103.7$ & $8291.9 \pm 73.6$ \\
\hline Light physical activity $\left(\min \cdot d^{-1 a y}{ }^{-1}\right)^{\star} \dagger$ & $360.9 \pm 4.8$ & $391.6 \pm 2.2$ & $432.0 \pm 3.4$ & $425.9 \pm 2.2$ \\
\hline MVPA $\left(\min \cdot \mathrm{day}^{-1}\right)^{*} \dagger$ & $23.8 \pm 1.1$ & $42.3 \pm 0.7$ & $43.0 \pm 1.1$ & $53.8 \pm 0.8$ \\
\hline Bouted MVPA (min·day $\left.{ }^{-1}\right)^{\star} \dagger$ & $4.3 \pm 0.4$ & $14.1 \pm 0.4$ & $12.5 \pm 0.6$ & $17.6 \pm 0.5$ \\
\hline
\end{tabular}

Data are shown as mean \pm SEM.

*Significant difference between ranks: $p<0.001$.

†Significant linear trend by increasing rank: $p<0.001$.

MVPA, moderate and vigorous physical activity; SGPALS, Saltin-Grimby Physical Activity Level Scale; VM CPM, vector magnitude counts per minute.

time questionnaire, processed as both ranking and volume calculations, against accelerometry as our criterion measure. We found positive associations between ranking of physical activity in both the SGPALS and the PAFID questionnaire, and accelerometry measured physical activity. When processed as calculated volume, we found at best moderate correlations between self-reported and accelerometry measured physical activity. The IPAQ sitting question showed weak correlations and a narrow range in mean accelerometry measured sedentary time between quartile 1 and 4 in the IPAQ (within 1 hour per day).

\section{The validity of the questionnaires}

We found positive associations between accelerometry measured physical activity and ranking in the SGPALS. For example, those who categorised themselves in the lowest rank in the combined SGPALS accumulated on average 4900 steps and 23 min of MVPA per day, respectively, which is about half of the accumulated steps and MVPA per day in the highest rank ( 8290 steps and 53 min MVPA). This illustrates the ability of the SGPALS to rank physical activity levels in a large cohort of adults and elderly. The findings of positive associations between SGPALS rankings and accelerometry measured physical activity are consistent with previous validation studies of the SGPALS. ${ }^{23} 26$
In contrast, when estimating PAL volume scores from the SGPALS, the correlations between PAL scores and accelerometry measured physical activity were weak, which accentuates the biasses associated with self-reported physical activity. ${ }^{2-46}$ These findings may suggest that the biases associated with self-reported physical activity are more pronounced when physical activity is processed as total volume (eg, PAL, MET-hours per week) compared with ranking individuals according to their self-reported physical activity.

We found positive associations between quartiles of MET-hours per week from the PAFID questionnaire and accelerometry estimates. However, correlations between MET-hours per week from the PAFID questionnaire and accelerometry estimates were weak and only moderate for bouted MVPA. Such correlations are consistent with a previous validation study of the PAFID questionnaire. ${ }^{18}$ As with the SGPALS, ranking by quartiles may be the preferred way of expressing self-reported physical activity.

Although we found a positive association between quartiles of reported sitting hours from the IPAQ and accelerometry measured sedentary time, the narrow 1 hour range between quartile 1 and 4 in the IPAQ suggests small differences in real sedentary time between quartiles in the IPAQ.

Table 5 Quartiles of MET-hours per week from the PAFID ( $n=5902)$

\begin{tabular}{|c|c|c|c|c|}
\hline Quartiles & $1(n=1355)$ & $2(n=1498)$ & $3(n=1473)$ & $4(n=1576)$ \\
\hline Range MET-hours $\cdot$ week $^{-1}$ & $0.00-2.50$ & $2.81-9.00$ & $11.25-11.25$ & $15.00-45.00$ \\
\hline MET-hours $\cdot$ week $^{-1}$ & $1.03 \pm 0.02$ & $5.13 \pm 0.03$ & $11.25 \pm 0.00$ & $21.44 \pm 0.16$ \\
\hline VM CPM $^{*} \dagger$ & $448.3 \pm 4.4$ & $508.9 .5 \pm 4.3$ & $557.4 \pm 4.3$ & $610.5 \pm 4.6$ \\
\hline Steps per day ${ }^{\star} \dagger$ & $5207.8 \pm 62.1$ & $6342.9 \pm 63.4$ & $7441.3 \pm 69.9$ & $8559.4 \pm 78.2$ \\
\hline Light physical activity $\left(\min \cdot \text { day }^{-1}\right)^{\star} \dagger$ & $386.4 \pm 2.6$ & $406.2 \pm 2.3$ & $407.9 \pm 2.3$ & $404.9 \pm 2.0$ \\
\hline MVPA $\left(\min \cdot \text { day }^{-1}\right)^{\star} \dagger$ & $25.9 \pm 0.7$ & $35.2 \pm 0.7$ & $44.6 \pm 0.7$ & $55.8 \pm 0.8$ \\
\hline Bouted MVPA (min $\cdot$ day $\left.^{-1}\right)^{\star} \dagger$ & $3.9 \pm 0.2$ & $9.4 \pm 0.3$ & $15.2 \pm 0.4$ & $23.7 \pm 0.5$ \\
\hline
\end{tabular}

Data are shown as mean \pm SEM.

*Significant difference between quartiles: $p<0.001$.

†Significant trend by increasing quartile: $p<0.001$.

Bouted MVPA, moderate and vigorous physical activity in $\geq 10$ min bouts; MET, metabolic equivalent of tasks; MVPA, moderate and vigorous physical activity; PAFID, Physical Activity Frequency, Intensity and Duration; VM CPM, vector magnitude counts per minute. 
Table 6 Quartiles of reported hours sitting from the IPAQ sitting question, for a typical week and weekend day combined, and the association with accelerometry measured sedentary time

\begin{tabular}{|c|c|c|c|c|}
\hline Quartiles & $1(n=783)$ & $2(n=1432)$ & $3(n=1277)$ & $4(n=1359)$ \\
\hline Range IPAQ (hours day $^{-1}$ ) & $0.0-4.0$ & $4.0-5.0$ & $6.0-7.0$ & $8.0-24.0$ \\
\hline IPAQ (hours $\cdot$ day $^{-1}$ ) & $2.8 \pm 0.03$ & $4.7 \pm 0.03$ & $6.6 \pm 0.5$ & $9.7 \pm 1.9$ \\
\hline Accelerometry sedentary time (hours $\cdot$ day $\left.^{-1}\right)^{*} \dagger$ & $9.3 \pm 0.06$ & $9.6 \pm 0.04$ & $9.9 \pm 0.04$ & $10.3 \pm 0.04$ \\
\hline
\end{tabular}

Data are shown mean \pm SEM.

*Significant difference between quartiles: $p<0.001$.

†Significant trend by increasing quartile: $p<0.001$.

IPAQ, International Physical Activity Questionnaire.

\section{Strengths}

This study included one of the largest sample sizes in validation studies of PAQs, allowing us to assess the validity in a large heterogeneous sample with high participation rate, which may represent the heterogeneous population to a larger extent than smaller sample sizes. Consequently, the generalisability of the findings from this study is likely high, at least for adults $>40$ years in western high-income countries.

\section{Limitations}

Validation of PAQs is challenging. First of all, in contrast to doubly labelled water, which is the gold standard for measuring free-living energy expenditure,${ }^{40} 41$ there is no gold standard to measure all aspects (domain, context, intensity, duration, frequency and volume) of physical activity accurately. ${ }^{164243}$

Second, we used specific cut-points to split intensity in the accelerometry data, which may not reflect the intended intensity by the participants when answering the PAQs. However, in general, accelerometry measured physical activity shows greater validity than self-reported methods when compared with energy expenditure estimated from doubly labelled water, ${ }^{44-46}$ thus, a criterion validation from accelerometry can be considered applicable.

Third, the time periods for self-reported physical activity and sedentary time were not aligned with the accelerometry assessment. However, most physical activity instruments are intended to assess habitual physical activity. ${ }^{47}$ Moreover, as all included questionnaires (SGPALS: Kappa: $0.69,{ }^{16}$ PAFID: Spearman's rho $(\rho): 0.76$ to 87$),{ }^{18}$ IPAQ: $\rho: 0.50$ to $0.94^{21}$ ) and a 7 day accelerometry recording with four valid days (intraclass correlation: 0.8$)^{47}$ are found to provide acceptable reliability, we believe that the included instruments provide reasonable estimates of habitual physical activity and our comparison is justified.

Finally, the waist placement of accelerometers in our study does not assess sitting per se. Other placements, such as thigh-worn accelerometers, may be more suitable for validating self-reported sitting. Nevertheless, our results are consistent with a previous study that employed thigh-worn accelerometers, ${ }^{48}$ suggesting that hip-worn accelerometers are able to measure sedentary time more accurately than self-reported methods.

\section{CONCLUSION}

Ranking of physical activity seems to be the preferred method to process PAQs, exhibiting higher validity against accelerometry measures than volume calculations of self-reported physical activity. Self-reported sedentary time poorly reflects accelerometry measured sedentary time. The two PAQs can be used for ranking individuals into different physical activity categories supporting previous studies using these instruments when assessing associations with health outcomes.

\section{Author affiliations}

${ }^{1}$ Faculty of Health Sciences, School of Sport Sciences, UiT Arctic University of Norway, Tromso, Troms, Norway

${ }^{2}$ Faculty of Health Sciences, Department of Community Medicine, UiT Arctic University of Norway, Tromso, Troms, Norway

${ }^{3}$ Faculty of Health and Sport Sciences, Department of Sport Science and Physical Education, University of Agder, Kristiansand, Vest-Agder, Norway

${ }^{4}$ MRC Epidemiology Unit, University of Cambridge, Cambridge, UK

${ }^{5}$ Department of Sports Science and Clinical Biomechanics, Faculty of Health Sciences, University of Southern Denmark, Odense, Syddanmark, Denmark

${ }^{6}$ Faculty of Science and Technology, Department of Computer Science, UiT Arctic University of Norway, Tromso, Troms, Norway

${ }^{7}$ Department of Sports Medicine, Norwegian School of Sport Sciences, Oslo, Oslo, Norway

${ }^{8}$ Department of Chronic Diseases and Ageing, Norwegian Institute of Public Health, Oslo, Oslo, Norway

\section{Twitter Edvard H Sagelv @edvardhsagelv}

Acknowledgements The authors would like to acknowledge PhD Ola Løvsletten for his advice on statistical analyses.

Contributors Significant manuscript writer: EHS. Significant manuscript reviewer/reviser: BM, UE, LAH, SB, BHH, JJ and AH. Concept and design: EHS $\mathrm{BM}, \mathrm{UE}$ and LAH. Data acquisition, analysis and interpretation: EHS, BM, LAH, $\mathrm{UE}, \mathrm{SB}, \mathrm{BHH}, \mathrm{JJ}$ and AH. Statistical expertise: Ola Løvsletten mentioned in acknowledgements.

Funding The article processing charges are funded by the publication fund at the University Library at UiT the Arctic University of Norway. The work of Edvard H Sagelv and Jonas Johansson are funded by the Population Studies in the High North (Befolkningsundersøkelser i Nord: BiN), an internally funded project by UiT The Arctic University of Norway. The work of Søren Brage is funded by the UK Medical Research Council (MC_UU_12015/3) and the NIHR Biomedical Research Centre in Cambridge (IS-BRC-1215-20014). The remaining authors were funded internally by their institutional tenures/positions.

Competing interests None declared.

Patient consent for publication Not required.

Ethics approval Troms $\emptyset 7$ and this present study were approved by the Regional Ethics Committee for Medical Research (REC North ref. 2014/940 and 2016/758410, respectively) and the Norwegian Data Protection Authority.

Provenance and peer review Not commissioned; externally peer reviewed. 
Data availability statement Data may be obtained from a third party and are not publicly available. The data that support the findings of this study are available from the Troms $ø$ Study but restrictions apply to the availability of these data, which were used under license for the current study, and so are not publicly available. The data can be made available from the Tromsø Study upon application to the Data and Publication Committee for the Tromsø Study.

Open access This is an open access article distributed in accordance with the Creative Commons Attribution Non Commercial (CC BY-NC 4.0) license, which permits others to distribute, remix, adapt, build upon this work non-commercially, and license their derivative works on different terms, provided the original work is properly cited, appropriate credit is given, any changes made indicated, and the use is non-commercial. See: http://creativecommons.org/licenses/by-nc/4.0/.

\section{ORCID iD}

Edvard H Sagelv http://orcid.org/0000-0003-2213-5806

\section{REFERENCES}

1 Knuth AG, Hallal PC. Temporal trends in physical activity: a systematic review. J Phys Act Health 2009;6:548-59.

2 Sallis JF, Saelens BE. Assessment of physical activity by self-report: status, limitations, and future directions. Res Q Exerc Sport 2000;71 Suppl 2:1-14.

3 Prince SA, Adamo KB, Hamel ME, et al. A comparison of direct versus self-report measures for assessing physical activity in adults: a systematic review. Int J Behav Nutr Phys Act 2008;5:56.

4 Silsbury Z, Goldsmith R, Rushton A. Systematic review of the measurement properties of self-report physical activity questionnaires in healthy adult populations. BMJ Open 2015;5:e008430.

5 Lee PH, Macfarlane DJ, Lam TH, et al. Validity of the International physical activity questionnaire short form (IPAQ-SF): a systematic review. Int J Behav Nutr Phys Act 2011;8:115.

6 Helmerhorst HJF, Brage S, Warren J, et al. A systematic review of reliability and objective criterion-related validity of physical activity questionnaires. Int J Behav Nutr Phys Act 2012;9:103.

7 Lee I-M, Shiroma EJ, Lobelo F, et al. Effect of physical inactivity on major non-communicable diseases worldwide: an analysis of burden of disease and life expectancy. Lancet 2012;380:219-29.

8 Wen CP, Wai JPM, Tsai MK, et al. Minimum amount of physical activity for reduced mortality and extended life expectancy: a prospective cohort study. Lancet 2011;378:1244-53.

9 Lear SA, Hu W, Rangarajan S, et al. The effect of physical activity on mortality and cardiovascular disease in 130000 people from 17 high-income, middle-income, and low-income countries: the PURE study. Lancet 2017;390:2643-54.

10 Blair SN. Physical inactivity: the biggest public health problem of the 21st century. Br J Sports Med 2009;43:1-2.

11 Morris JN, Heady JA, Raffle PA, et al. Coronary heart-disease and physical activity of work. Lancet 1953;262:1111-20.

12 Carnethon MR, Activity P. Physical activity and cardiovascular disease: how much is enough? Am J Lifestyle Med 2009;3:44S-9.

13 Haennel RG, Lemire F. Physical activity to prevent cardiovascular disease. how much is enough? Can Fam Physician 2002;48:65-71.

14 Messerli FH, Ketelhut RG, Ketelhut K. Cardiovascular risk factors and physical activity: how much is enough? Arch Intern Med 1999:159:882-3.

15 Saltin B, Grimby G. Physiological analysis of middle-aged and old former athletes. Comparison with still active athletes of the same ages. Circulation 1968;38:1104-15.

16 Grimby G, Börjesson M, Jonsdottir IH, et al. The "Saltin-Grimby Physical Activity Level Scale" and its application to health research. Scand J Med Sci Sports 2015;25 Suppl 4:119-25.

17 Rödjer L, Jonsdottir IH, Rosengren A, et al. Self-Reported leisure time physical activity: a useful assessment tool in everyday health care. BMC Public Health 2012;12:693.

18 Kurtze N, Rangul V, Hustvedt B-E, et al. Reliability and validity of self-reported physical activity in the Nord-Trøndelag health study: Hunt 1. Scand J Public Health 2008;36:52-61.

19 Ekelund U, Steene-Johannessen J, Brown WJ, et al. Does physica activity attenuate, or even eliminate, the detrimental association of sitting time with mortality? A harmonised meta-analysis of data from more than 1 million men and women. Lancet 2016;388:1302-10.

20 de Rezende LFM, Rodrigues Lopes M, Rey-López JP, et al. Sedentary behavior and health outcomes: an overview of systematic reviews. PLoS One 2014;9:e105620.

21 Craig CL, Marshall AL, Sjöström M, Sjögren M, et al. International physical activity questionnaire: 12-country reliability and validity. Med Sci Sports Exerc 2003;35:1381-95.
22 Wilhelmsen L, Tibblin G, Aurell M, et al. Physical activity, physical fitness and risk of myocardial infarction. Adv Cardiol 1976;18:217-30.

23 Emaus A, Degerstrøm J, Wilsgaard T, et al. Does a variation in selfreported physical activity reflect variation in objectively measured physical activity, resting heart rate, and physical fitness? results from the Tromso study. Scand J Public Health 2010;38:105-18.

24 Graff-Iversen S, Anderssen SA, Holme IM, et al. Two short questionnaires on leisure-time physical activity compared with serum lipids, anthropometric measurements and aerobic power in a suburban population from Oslo, Norway. Eur J Epidemiol 2008;23:167-74

25 Johansson G, Westerterp KR. Assessment of the physical activity level with two questions: validation with doubly labeled water. Int $J$ Obes 2008;32:1031-3.

26 Matthiessen J, Biltoft-Jensen A, Rasmussen LB, et al. Comparison of the Danish physical activity questionnaire with a validated position and motion instrument. Eur J Epidemiol 2008;23:311-22.

27 Loe H, Rognmo Øivind, Saltin B, et al. Aerobic capacity reference data in 3816 healthy men and women $20-90$ years. PLoS One 2013;8:e64319.

28 Lindén V, Lindén V. Vitamin D and serum cholesterol. Scand J Soc Med 1975;3:83-5.

29 Thelle DS, Førde OH, Try K, et al. The Tromsø heart study. Acta Med Scand 1976;200:107-18.

30 Miller NE, Thelle DS, Førde OH, et al. The Tromsø heart-study. high-density lipoprotein and coronary heart-disease: a prospective case-control study. Lancet 1977;1:965-8.

31 Nordstoga AL, Zotcheva E, Svedahl ER, et al. Long-Term changes in body weight and physical activity in relation to all-cause and cardiovascular mortality: the HUNT study. Int J Behav Nutr Phys Act 2019;16:45

32 Jacobsen BK, Eggen AE, Mathiesen EB, et al. Cohort profile: the Tromso study. Int J Epidemiol 2012;41:961-7.

33 Wareham NJ, Jakes RW, Rennie KL, et al. Validity and repeatability of a simple index derived from the short physical activity questionnaire used in the European prospective investigation into cancer and nutrition (EPIC) study. Public Health Nutr 2003;6:407-13.

34 Ainsworth BE, Haskell WL, Leon AS, et al. Compendium of physical activities: classification of energy costs of human physical activities. Med Sci Sports Exerc 1993;25:71-80.

35 Ainsworth BE, Haskell WL, Herrmann SD, et al. 2011 compendium of physical activities: a second update of codes and Met values. Med Sci Sports Exerc 2011;43:1575-81.

36 Hecht A, Ma S, Porszasz J, et al. Methodology for using long-term accelerometry monitoring to describe daily activity patterns in COPD. COPD 2009;6:121-9.

37 Peterson NE, Sirard JR, Kulbok PA, et al. Validation of accelerometer thresholds and inclinometry for measurement of sedentary behavior in young adult university students. Res Nurs Health 2015;38:492-9.

38 Sasaki JE, John D, Freedson PS. Validation and comparison of ActiGraph activity monitors. J Sci Med Sport 2011;14:411-6.

39 Schober P, Boer C, Schwarte LA. Correlation coefficients: appropriate use and interpretation. Anesth Analg 2018;126:1763-8.

40 Westerterp KR. Assessment of physical activity: a critical appraisal. Eur J Appl Physiol 2009;105:823-8.

41 Lifson N, Gordon GB, McCLINTOCK R, Mc CR. Measurement of total carbon dioxide production by means of D2O18. J Appl Physiol 1955;7:704-10.

42 Hills AP, Mokhtar N, Byrne NM. Assessment of physical activity and energy expenditure: an overview of objective measures. Front Nutr 2014;1:5.

43 Dencker M, Andersen LB. Accelerometer-measured daily physical activity related to aerobic fitness in children and adolescents. $J$ Sports Sci 2011;29:887-95.

44 Plasqui G, Westerterp KR. Physical activity assessment with accelerometers: an evaluation against doubly labeled water. Obesity 2007;15:2371-9.

45 Chomistek AK, Yuan C, Matthews CE, et al. Physical activity assessment with the ActiGraph GT3X and doubly labeled water. Med Sci Sports Exerc 2017;49:1935-44.

46 Bonn SE, Rimm EB, Matthews CE, et al. Associations of sedentary time with energy expenditure and anthropometric measures. Med Sci Sports Exerc 2018:50:2575-83.

47 Baranowski T, Mâsse LC, Ragan B, et al. How many days was that? we're still not sure. but we're asking the question better! Med Sci Sports Exerc 2008;40:544-9.

48 Lagersted-Olsen J, Korshøj M, Skotte J, et al. Comparison of objectively measured and self-reported time spent sitting. Int $J$ Sports Med 2014;35:534-40. 